\title{
Polyphenols, Ascorbic Acid and Carotenoids Contents and Antioxidant Properties of Habanero Pepper (Capsicum chinense) Fruit
}

\author{
Maira Rubi Segura Campos ${ }^{1}$, Karen Ramírez Gómez ${ }^{1}$, Yolanda Moguel Ordoñez ${ }^{2}$, \\ David Betancur Ancona ${ }^{1}$
}

${ }^{1}$ Faculty of Chemical Engineering, Autonomous University of Yucatán, Mérida, Mexico; ${ }^{2}$ National Institute for Forestry, Agriculture and Livestock (INIFAP), Experimental Campus of Mocochá, Mocochá, México.

Email: bancona@uady.mx

Received March $15^{\text {th }}, 2013$; revised April 15 ${ }^{\text {th }}, 2013$; accepted April $23^{\text {rd }}, 2013$

Copyright (C) 2013 Maira Rubi Segura Campos et al. This is an open access article distributed under the Creative Commons Attribution License, which permits unrestricted use, distribution, and reproduction in any medium, provided the original work is properly cited.

\begin{abstract}
Their high bioactive compounds content and importance as dietary antioxidants has increased interest in Capsicum fruit. The fruit of seven Capsicum chinense Jacq. var. habanero genotypes grown in Yucatan, Mexico, were analyzed to quantify their phenolic compounds, carotenoids and ascorbic acid contents, and to measure their free radical scavenging (ABTS assay) and antioxidant activities ( $\beta$-carotene/linoleic acid assay). Phenolics ( 20.54 to $20.75 \mathrm{mg} / 100 \mathrm{~g}$ sample), carotenoids (1.00 to $1.26 \mathrm{mg} / 100 \mathrm{~g}$ sample) and ascorbic acid contents ( 187.24 to $281.73 \mathrm{mg} / 100 \mathrm{~g}$ sample) varied between genotypes. Trolox equivalent antioxidant capacity (TEAC) ranged from 1.55 to $3.23 \mathrm{mM} / \mathrm{mg}$ sample. During the 120-min decolorization trial, antioxidant capacity decreased over time in the studied genotypes. Values ranged from $36 \%$ to $57 \% \beta$-carotene bleaching during the first 30 minutes. Fruit from all seven studied genotypes are good antioxidant sources and hold promise as natural ingredients in functional foods.
\end{abstract}

Keywords: Capsicum chinense Jacq; Phenolic Compounds; Carotenoids Content; Ascorbic Acid Content; Antioxidant Activities

\section{Introduction}

Antioxidants are of interest because they reduce free radicals and reactive oxygen species (ROS) in the organism. ROS and other free radicals are generated as part of normal cellular metabolism and in response to environmental factors such as ultraviolet irradiation [1]. Accumulation of these highly reactive molecules in cells can damage cellular components such as lipids, membranes, nucleic acids and proteins. This oxidative stress can directly and/or indirectly lead to human diseases such as cardiovascular disease and cancer. The human body is equipped with an antioxidant defense system that deactivates these highly reactive free radicals [2]. One of the most practical ways of managing free radical activity in the body is through diet. Dietary antioxidants may play an important role in protecting against cell damage caused by free radicals by acting as radical scavengers, reducing agents and quenchers of singlet oxygen formation, and by forming complexes with pro-oxidant metals [3].
Carotenoids impart orange and red colors in vegetables. The carotenoids in peppers include capsanthin and carotene. The yellow-orange color of peppers is formed by $\alpha$ and $\beta$-carotene, zeaxanthin, lutein and $\beta$-cryptoxanthin [4]. Beta-carotene is a hydrocarbon carotenoid found widely in the chloroplasts of higher plants, and exercises pro-vitamin A and powerful antioxidant activities. Carotenoids' cancer-preventive activities have been associated with their antioxidant properties [5]. Perera and Yen [6] reported that consumption of carotenoid-rich foods reduces the incidence of several disorders such as cancers, cardiovascular diseases, age-related macular degeneration, cataracts, diseases related to compromised immune function, and other degenerative diseases.

Plant phenols include simple phenols, flavonoids, anthocyanins, lignans and lignins, stilbenes and tannins. Phenols function as antioxidants with properties similar to vitamins $\mathrm{C}$ and $\mathrm{E}$, and $\beta$-carotene, and have received extensive study. A wide variety of spice-derived phenolic 
compounds, such as capsaicin, possess potent antimutagenic and anticarcinogenic properties [7]. Phenolic compounds cannot be produced by the human organism and are acquired mainly through diet. Knowledge about the nutritional and therapeutic role of dietary phenolic antioxidants is essential for development of functional foods, which are conventional foods with augmented health benefits [2].

Ascorbic acid is a required human nutrient, and functions primarily as an antioxidant in biological systems, preventing common degenerative processes. Testing of ascorbic acid derivatives on cancer cells showed ascorbic acid esters to have promising anticancer activity [8]. Ascorbic acid as found in most fruits and vegetables also protects against heart disease, high cholesterol, high blood pressure and cancer [5].

Capsicum species have been domesticated since the advent of agriculture and have formed part of the human diet since at least 7500 BCE. Along with beans (Phaseolus spp.), corn (Zea mays L.) and cucurbits (Cucurbitaceae), Capsicum species were among the first plants cultivated in the Americas. Indigenous peoples in the Americas began growing chilies between 5200 and $3400 \mathrm{BCE}$, making them some of the oldest cultivated crops in the Americas. Ancient farmers began the selection process with wild Capsicum varieties, leading eventually to the myriad varieties known today. A member of the family Solanaceae, the Capsicum genus includes five species commonly recognized as domesticated: $C$. annuиm, $C$. baccatum, C. chinense, $C$. frutescens and C. pubescens. There are also approximately 20 documented wild species [9].

Mexico is one of the principal centers of origin and domestication of the genus Capsicum. Some variants in Mexico are known and used primarily in certain regions. For example, five variants are common in Yucatan state: Habanero (C. chinense, Jacq.); Ya'xik (green pepper); Xcatik (sweet pepper); Chowak, Picopaloma, Sukurre (C. annuum L.), grown in cornfields and backyard gardens; and $M a$ 'xik (C. annuum var. aviculare Dierb. D'Arcy \& Eshbaugh), grown in a semi-wild state in backyards [10]. Habanero pepper fruitis known to be an excellent source of phytochemicals, including vitamins $\mathrm{A}$ and $\mathrm{C}$, phenolic compounds, flavonoids and carotenoids [5]. Hot chili peppers are widely consumed in Mexico, with an average annual per capita intake of approximately 7 to $9 \mathrm{~kg}$, making it the second most consumed vegetable after tomatoes [11]. Such a widely consumed vegetable with various potential health benefits merits characterization of its bioactive compounds content to better understand their possible applications and increase consumer awareness of these benefits. The present study objective was to quantify polyphenols, carotenoids and ascorbic acid levels, and measure free radical scavenging activity using an
ABTS decolorization assay and antioxidant activity with a b-carotene assay in habanero pepper Capsicum chinense Jaq. genotypes grown in Yucatan state, Mexico.

\section{Materials and Methods}

\subsection{Capsicum chinense Jacq. Genotypes}

Capsicum chinense Jacq. Genotypes were donated by the germ plasm bank of the Instituto Nacional de Investigaciones Forestales, Agrícolas y Pecuarias (INIFAP) of Mexico from the September 2011 harvest in Yucatán, Mexico. Material was selected based on mature fruit color 82 days after transplantation. Selected colors and materials were orange (Orange and L-184); red (Red and L-149); yellow (L-110 and L-36); and brown (L-37). Fruitfrom the selected genotypes were refrigerated during 12 hours before their use. After that fruits were ground in a blender at a 1:2 (fruit:distilled water) ratio. Samples of the fruit were frozen and dried at $-45^{\circ} \mathrm{C}$ and $133 \times 10^{-3} \mathrm{mbar}$ in a lyophilizer (Labconco Free Zone 4.5, Kansas City, MI, USA).

\subsection{Capsicum chinense Jacq. Extracts}

Extracts were produced by first suspending $1 \mathrm{~g}$ (d.b.) lyophilized sample in $20 \mathrm{~mL}$ methanol aqueous solution at $80 \%(\mathrm{v} / \mathrm{v})$ and stirring for $3 \mathrm{~h}$ at room temperature. The suspension was centrifuged at $2500 \times \mathrm{g}$ for $15 \mathrm{~min}$ (Mistral 3000i, Curtin Matheson Sci.), the supernatant separated and a second extraction done. The two supernatants were mixed and filtered through No. 41 Whatman paper.

\subsection{Total Polyphenols}

Total polyphenols concentration in all samples was quantified by the Folin-Ciocalteau method, according to Singleton et al. [12]. The reaction mixture consisted of 500 $\mathrm{mL}$ sample in $4.5 \mathrm{~mL}$ water to which a solution of 200 $\mathrm{mL}$ Folin-Ciocalteau and $500 \mathrm{~mL}$ saturated $\mathrm{Na}_{2} \mathrm{CO}_{3}$ was added. This mixture was stirred and $4.3 \mathrm{~mL}$ distilled water added. After $1 \mathrm{~h}$, absorbance was read at $765 \mathrm{~nm}$ (Thermospectronic Genesis 10 uv, Madison, WI, USA). Total polyphenol content was calculated as Trolox equivalents. Trolox standard solutions were used for constructing the calibration curve. Total phenols content was expressed as mg Trolox equivalents per $100 \mathrm{~g}$ of sample.

\subsection{Total Carotenoids}

Total carotenoids concentration was quantified according to Rodriguez-Amaya and Kimura [13]. Briefly, $1 \mathrm{~g}$ fresh sample was homogenized in $20 \mathrm{~mL}$ acetone and the supernatant decanted. This process was repeated until attaining complete removal of all pigments. The sample was filtered and washed with $30 \mathrm{~mL}$ acetone, the acetone 
evaporated and the dry sample dissolved in $60 \mathrm{~mL}$ petroleum ether. The resulting solution was filtered, transferred quantitatively to a $100 \mathrm{~mL}$ volumetric flask, and volume completed with petroleum ether. Of this solution, $2 \mathrm{~mL}$ were placed in a test tube with $8 \mathrm{~mL}$ petroleum ether. Absorbance was read at $475 \mathrm{~nm}$ (Thermospectronic Genesis 10 uv, Madison, Wi, USA) and concentration calculated with a $\beta$-carotene curve.

\subsection{Ascorbic Acid}

Ascorbic acid concentration in all samples was quantified using the official AOAC titrimetric method [14]. Briefly, $2 \mathrm{~mL}$ of $3 \%$ metaphosphoric acid- $8 \%$ acetic acid sample extracts were titrated with indophenol solution (25\% 2,6-dichlorophenol and $2 \% \mathrm{NaHCO}_{3}$ in water) until a light but distinct rose pink color appeared and persisted for more than 5 seconds. Indophenol concentration was expressed as $\mathrm{mg}$ of ascorbic acid equivalent to $1 \mathrm{~mL}$ of reagent. Ascorbic acid content was expressed as $\mathrm{mg}$ of indophenol equivalents per $100 \mathrm{~g}$ of sample.

\subsection{ABTS Decolorization Assay}

Antioxidant activity was analyzed following Pukalskas et al. [15]. The $\mathrm{ABTS}^{\bullet+}$ radical cation was produced by reacting ABTS with potassium per sulfate. To prepare the stock solution, ABTS was dissolved at a $2 \mathrm{mM}$ concentration in $50 \mathrm{~mL}$ phosphate-buffered saline (PBS) prepared from $4.0908 \mathrm{~g} \mathrm{NaCl}, 0.1347 \mathrm{~g} \mathrm{KH}_{2} \mathrm{PO}_{4}, 0.7098 \mathrm{~g}$ $\mathrm{Na}_{2} \mathrm{HPO}_{4}$, and $0.0749 \mathrm{~g} \mathrm{KCl}$ dissolved in $500 \mathrm{~mL}$ ultrapure water. If $\mathrm{pH}$ was lower than 7.4, it was adjusted with $\mathrm{NaOH}$. A $70 \mathrm{mM} \mathrm{K}_{2} \mathrm{~S}_{4} \mathrm{O}_{8}$ solution in ultrapure water was prepared. ABTS radical cation was produced by reacting $10 \mathrm{~mL}$ ABTS stock solution with $40 \mathrm{~mL} \mathrm{~K}_{2} \mathrm{~S}_{4} \mathrm{O}_{8}$ solution and allowing the mixture to stand in darkness at room temperature for $16-17 \mathrm{~h}$ before use. The radical was stable in this form for more than 2 days when stored in darkness at room temperature.

Antioxidant compound content in all samples was analyzed by diluting the ABTS ${ }^{\bullet+}$ solution with PBS to an absorbance of $0.800 \pm 0.03 \mathrm{AU}$ at $734 \mathrm{~nm}$. After adding $990 \mathrm{~mL}$ diluted $\mathrm{ABTS}^{\bullet+}$ solution $\left(\mathrm{A}_{734 \mathrm{~nm}}=0.800 \pm 0.03\right)$ to $10 \mathrm{~mL}$ antioxidant compound or Trolox standard (final concentration $0.5-3.5 \mathrm{mM}$ ) in PBS, absorbance was read at ambient temperature exactly 6 min after initial mixing. All analyses were run in triplicate. The percentage decrease in absorbance at $734 \mathrm{~nm}$ was calculated and plotted as a function of the Trolox concentration for the standard reference data. The radical scavenging activity of the tested samples, expressed as inhibition percentage $\left(\% I_{s}\right)$, was calculated with the equation:

$$
\% I_{s}=\left[\left(A_{B}-A_{A}\right) / A_{B}\right] \times 100
$$

where $A_{B}$ is absorbance of the blank sample $(\mathrm{t}=0)$, and $A_{A}$ is absorbance of the sample with antioxidant after 6 min.

The Trolox equivalent antioxidant coefficient (TEAC) was quantified by a regression analysis of percent inhibition versus Trolox concentration using the following formula:

$$
\mathrm{TEAC}=\left(\% I_{s}-b\right) / m
$$

where $b$ is the intersection and $m$ is the slope.

\section{7. ß-Carotene Decolorization Assay}

Antioxidant activity was quantified according to Miller [16]. The assay is based on determining the decolorization exhibited by $\beta$-carotene in response to the action of linoleic acid oxidation products. In a test tube, $1 \mathrm{~mL} 0.2$ $\mathrm{mg} / \mathrm{mL} \beta$-carotene in chloroform was added to a mixture of $20 \mathrm{mg}$ linoleic acid and $200 \mathrm{mg}$ Tween 20 . The chloroform was evaporated and $50 \mathrm{~mL}$ bidistilled water added. Aliquots $(2.5 \mathrm{~mL})$ of this mixture were added to tubes containing $100 \mathrm{~mL}$ sample. Water was used as a reference blank and 2,6-di-tert-butyl-4-methyl phenol (BHT) dissolved in $96 \%$ ethanol was used as a positive control. Samples were incubated at $50^{\circ} \mathrm{C}$, aliquots taken at 30,60 , 90 and $120 \mathrm{~min}$, and absorbance measured at $470 \mathrm{~nm}$ (Thermospectronic Genesis 10 uv, Madison, WI, USA).

\subsection{Statistical Analysis}

All results were analyzed using descriptive statistics with a central tendency and dispersion measures. One-way ANOVAs were run to evaluate polyphenols, carotenoids and ascorbic acid contents, as well as ABTS and b-carotene decolorization assay results. A LSD multiple range test was applied to determine differences between treatments. All analyses were done according to Montgomery [17] and processed with the Statgraphics Plus version 5.1 software.

\section{Results and Discussion}

Hot peppers are known to be a good source of phenolic compounds such aspolyphenols, carotenoids and ascorbic acid. These phytochemicals exhibit high antioxidant activity, and their consumption has been linked to a decreased risk of developing chronic and degenerative diseases. We studied Capsicum chinense Jaq. var. Habanero pepper fruit, one of the most widely consumed hot peppers in southeast Mexico. Total polyphenols, total carotenoids and ascorbic acid contents, as well as antioxidant activity (TEAC and b-carotene assay), were quantified in seven $C$. chinense Jacq genotypes selected based on mature fruit color 82 days after transplantation. 


\subsection{Total Polyphenols}

Among phytochemicals, polyphenols are particularly interesting for their free radical scavenging properties and in vivo biological activities. Epidemiological studies have indicated a possible association between dietary polyphenols intake and risk of coronary heart disease and cancer [18]. Peppers (Capsicum sp.) are known for being rich in micronutrients and bioactive compounds (e.g. phenolic compounds), and are recognized as beneficial to health. Total polyphenols content in the studied genotypes ranged from 20.54 to $20.75 \mathrm{mg} / 100 \mathrm{~g}$ sample (Figure 1). Content was higher $(\mathrm{p}<0.05)$ in red (L-149 and red) and brown (L-37) genotypes, and did not differ $(\mathrm{p}>0.05)$ among yellow and orange genotypes.

Polyphenols are secondary metabolites widely distributed in plants [11]. Levels vary widely during growth and maturation and contribute to fruit pungency, bitterness, flavor and color [9]. The more intensely colored genotypes studied here had the highest polyphenols content, which agrees with previous reports of high phenolics content in red genotypes. Zhang and Hamauzu [19] examined phenolic compounds content in bell peppers (Capsicum annum L.) of different colors, and reported than phenolics content varied depending on color $(9.2-15.4 \mathrm{mg}$ GAE/100 g fresh weight). In phenolic extracts, green pepper had a higher $(\mathrm{p}<0.05)$ phenolics content than red and yellow peppers, while in methanol extracts red pepper had a higher phenolics contents than green and yellow peppers. The present results for Habanero genotypes are comparable to reported total phenolics content in Chiltepin (4.85 mg/g GAE) and Habanero fruits (5.92 $\mathrm{mg} / \mathrm{g}$ GAE) [11].

Phenolic compounds are an important group of secondary metabolites synthesized by plants as an adaptation to biotic and abiotic stress conditions (infection, wounding, water stress, cold stress, high visible light) [2]. In recent years, phenolic compounds have attracted increasing research interest because they are potentially powerful

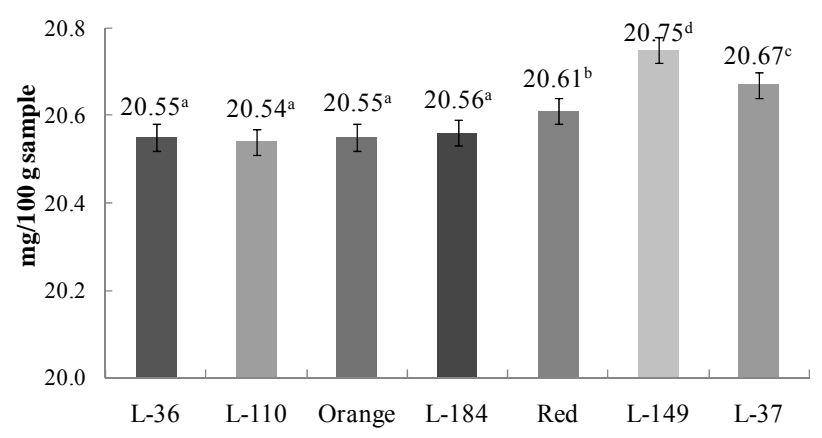

Figure 1. Polyphenols content in C. chinense Jacq. Genotypes. Data are presented as means $(n=3) .{ }^{a-c}$ Different superscript letters indicate statistical difference $(p<0.05)$. antioxidants that can protect the human organism from free radicals, formation of which is associated with normal natural metabolism of aerobic cells. The antiradical activity of flavonoids and phenolics is based on the redox properties of their hydroxy groups and the structural relationships between different parts of their chemical structure. Phenolic compounds cannot be produced by the human body, and thus must be acquired through the diet. Understanding the nutritional and therapeutic roles of dietary phenolic antioxidants is essential to developing functional foods, which are conventional foods with augmented health benefits [2]. In a study of total phenols content in mature $C$. chinense fruits from 63 accessions originally acquired from Belize, Brazil, Colombia, Ecuador, Mexico, Peru, Puerto Rico and the United States, an accession from Mexico (PI-438648) was found to contain the highest total phenols content (349 $\mu \mathrm{g} \cdot \mathrm{g}^{-1}$ fresh fruit) [5]. A phenols content double this has been reported for $C$. chinense Habanero (759.12 mg/100 g fresh weight) [20]. In a study of chemical composition and biological activities in two $C$. annuum cultivars (acuminatum small and cerasiferum) common in the Mediterranean diet, C. annuum var. acuminatum extract had a phenol content (970.2 $\mathrm{mg} / 100 \mathrm{~g}$ ) twice that of C. annuum var. cerasiferum (426.2 $\mathrm{mg} / 100 \mathrm{~g}$ ) [21]. These levels are higher than the total polyphenols contents reported for fresh red $(296 \mathrm{mg} / 100 \mathrm{~g})$, yellow $(284 \mathrm{mg} / 100 \mathrm{~g})$ and green $(215 \mathrm{mg} / 100 \mathrm{~g})$ peppers [22]. Hot peppers are clearly a good source of polyphenols, but compositional studies are needed to determine how variables such as cultivar, season and pre- and post-harvest conditions may affect pepper fruit chemical composition.

\subsection{Total Carotenoids}

Carotenoids are fat-soluble antioxidants found in many fruits and vegetables and are required for human epithetlial cellular differentiation [19]. Carotenoids content in the studied Habanero genotypes ranged from 1.00 to 1.26 $\mathrm{mg} / 100 \mathrm{~g}$ sample (Figure 2). No differences ( $\mathrm{p}>0.05$ ) were identified between the highest carotenoid levels in L-36, Orange, L-184 and L-37. Variation in carotenoids content in different colored peppers has also been reported in bell peppers (Capsicum annum L.), where yellow varieties had the highest levels and green peppers the lowest [19].

Carotenoids are terpenoid compounds formed by the condensation of eight isoprene units. Specific chemical groups present at the chain terminus determine carotenoid chromophore properties and allow their classification into two families based on color: red and yellow/ orange [23]. Capsicum fruit owe their intense coloring to carotenoid pigments [24], which coincides with the high carotenoid content observed here in all seven stud- 


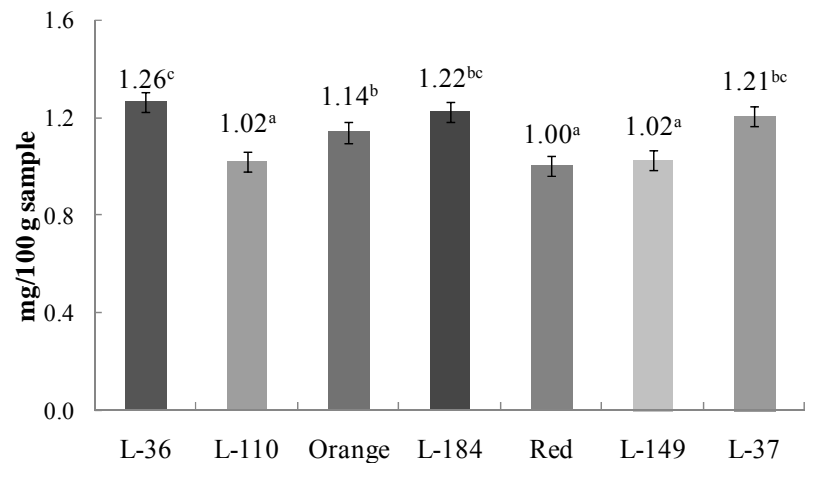

Figure 2. Carotenoids content in $C$. chinense Jacq. Genotypes. Data are presented as means $(n=3) .{ }^{a-c}$ Different superscript letters indicate statistical difference $(p<0.05)$.

ied genotypes. According to Nadeem et al. [9], peppers' attractive red color comes from various carotenoid pigments, including $\beta$-carotene with pro-vitamin A activity, and oxygenated carotenoids such as capsanthin, capsorubin and cryptocapsin, which are exclusive to this genus and are known to be effective free radical scavengers. Rodriguez-Maturino et al. [11] stated that carotenoids can act as antioxidants, with functions that include protection of membranes against damage by free radicals and retardation of ageing processes. In Chiltepin and Habanero fruit, they observed low red isochromic fraction carotenoids contents and suggest that this may result from the presence of a mutation (deletion) in the gene which codifies for the enzyme capsanthin-capsorrubin synthase (CCS) and thus prevents red pigment synthesis. They found that Chiltepin and Habanero fruits contain only yellow and orange carotenoids, making these varieties good prospects for developing new varieties with higher bioactive compound (e.g., yellow and orange carotenoids) contents. In their analysis of carotenoids content in mature $C$. chinense fruit from 63 accessions, Antonious et al. [5] found that accession PI-355817 (from Ecuador) contained the highest $\beta$-carotene concentrations $\left(8 \mathrm{mg} \cdot \mathrm{g}^{-1}\right.$ fresh fruit). These accessions were identified as potential candidates for mass production of antioxidants with health-promoting properties. Tundis et al. [21] stated that the primary reason for studying carotenoids in peppers is their bioactive effects, such as provitamin A activity, antioxidant actions, immune modulation and involvement in cell signaling. In a comparison of carotenoids content in two Capsicum annum L. cultivars, they observed that $C$. annuum var. acuminatum had a higher content $(324.2 \mathrm{mg} / 100 \mathrm{~g}$ dry matter) than $C$. annuиm var. cerasiferum $(133.9 \mathrm{mg} / 100 \mathrm{~g}$ dry matter). In a study ofcarotenoid composition in three dried $C$. annuum varieties widely consumed in Mexico, Collera-Zúñiga et al. [25] reported a mean carotenoid content of $6.76 \mathrm{mg} / 100$ $\mathrm{g}$ dry weight for var. Guajillo and a range of $7.0-7.5$ $\mathrm{mg} / 100 \mathrm{~g}$ dry weight for var. Ancho and var. Mulato. Differences in carotenoids content are probably due to the influence of genotype and maturity stages.

Carotenoids are known to play an important role in preventing oxidative damage, which is caused by free radicals in age-related diseases such as cancer. Most current carotenoids research is focused on their probable function as lipid antioxidants, which can protect against oxidation and other destructive processes mediated by singlet oxygen and free radicals, although more specific immune system effects are also receiving attention [21].

\subsection{Ascorbic Acid}

Peppers have the highest ascorbic acid content of the vegetables; for example, consumption of $100 \mathrm{~g}$ fresh weight of peppers provides $100 \%-200 \%$ of the recommended dietary allowance of ascorbic acid. Ascorbic acid content in the seven studied Habanero genotypes ranged from 187.24 to $281.73 \mathrm{mg} / 100 \mathrm{~g}$ sample (Figure 3). The Orange genotype had the highest level and the L-149 the lowest. Similar variation has been reported for bell peppers (Capsicum annum L.), in which red peppers had the highest ascorbic acid level, and green peppers the lowest [19]. The high ascorbic acid content of peppers is one of their primary nutritional qualities. Factors such as genotype, environment and fruit maturity affect levels of ascorbic acid and other nutritional compounds.

Ascorbic acid levels were high in all the studied genotypes, which coincides with reported increases in ascorbic acid content as pepper fruit matures; highest content is reached at full maturity [26]. Carotenoids, ascorbic acid, flavonoids, phenolic acids and other chemical constituent concentrations increase as peppers reach maturity [24]. In a study of several pepper cultivars, ascorbic acid was found to increase as color developed in some cultivars, but remained unchanged or diminished in others; black, purple, and white pepper fruit contained lower ascorbic acid levels compared to green, yellow, red, brown

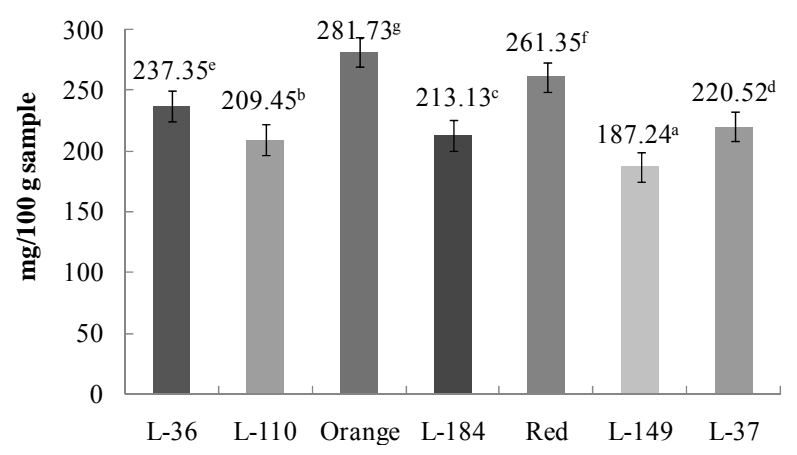

Figure 3. Acid ascorbic content in $C$. chinense Jacq. Genotypes. Data are presented as means $(n=3) .{ }^{a-g}$ Different superscript letters indicate statistical difference $(p<0.05)$. 
and orange peppers. High ascorbic acid levels have also been reported for pickled Serrano (584 mg ascorbic acid/ $100 \mathrm{~g}$ dry weight), fresh Serrano (1385 mg ascorbic acid/ $100 \mathrm{~g}$ dry weight), pickled Jalapeño (794 mg ascorbic acid/100 g dry weight), chipotle (694 mg ascorbic acid/ $100 \mathrm{~g}$ dry weight) and fresh Jalapeño peppers from three growing regions in the state of Chihuahua, Mexico: Meoqui (1696 mg ascorbic acid/100 g dry weight); Flores Magón (1185 mg ascorbic acid/100 g dry weight); and Ascención (2153 mg ascorbic acid/100 g dry weight) [27]. These authors concluded that the high variability in ascorbic acid content among Jalapeño samples may have been due to differences in growing conditions, maturity and particularly post harvest handling. In the study of the mature fruit of 63 C. chinense accessions by Antonious et al. [5], they reported that accessions PI-152452 (Brazil) and PI-360726 (Ecuador) contained the highest ascorbic acid concentrations (1.2 and $1.1 \mathrm{mg} \cdot \mathrm{g}^{-1}$ fresh fruit, respectively). These accessions were identified as potential candidates for mass production of antioxidants with healthpromoting properties. Over all, $C$. chinense Jacq. Is clearly an alternative source of phytochemicals such as ascorbic acid, a potent antioxidant.

\subsection{Antioxidant Activity}

\subsubsection{ABTS Decolorization Assay}

Trolox equivalent antioxidant capacity (TEAC) $(\mathrm{mM} / \mathrm{mg}$ sample) differed $(\mathrm{p}<0.05)$ between the genotypes, ranging from 1.55 to $3.23 \mathrm{mM} / \mathrm{mg}$ sample (Figure 4). The TEAC assay is based on scavenging of the $\mathrm{ABTS}^{\bullet+}$ radical cation by the antioxidants present in a sample. This radical is bluish-green in color, with maximum absorbance at $734 \mathrm{~nm}$ [28]. When antioxidant compounds are present in the reaction medium, they sequester the free radical, causing loss of color and a consequent reduction in absorbance that corresponds quantitatively to antioxidant concentration. TEAC values have also been reported for pickled Serrano (3988 mmol Trolox equivalent/100 g sample), fresh Serrano (4787 mmol Trolox equivalent/ $100 \mathrm{~g}$ sample), pickled Jalapeño (2776 mmol Trolox equivalent/100 g sample), chipotle (2864 mmol Trolox equivalent $/ 100 \mathrm{~g}$ sample) and fresh Jalapeño peppers from three growing regions in the state of Chihuahua, Mexico: Meoqui (5541 mmol Trolox equivalent/100 g sample); Flores Magón (3513 mmol Trolox equivalent/100 g sample); and Ascención (5211 mmol Trolox equivalent/100 g sample) [27]. In their study of Chiltepin and Habanero varieties, Rodriguez-Maturino et al. [11] suggested that differences in total antioxidant activity in peppers may be attributed to causes such as fertilization, fruit maturity and temperature. Their results showed no correlation between total phenolic compounds and antioxidant capacity in Chiltepin (11.10 mg of GAE/g of dry weight) and Ha- banero ( $8.20 \mathrm{mg}$ of GAE/g of dry weight) fruit, which may indicate that antioxidant capacity could be affected by the presence of phytochemicals such as carotenoids.

Scavenging ability (\%) also varied significantly $(\mathrm{p}<$ 0.05 ) between the genotypes, ranging from $94.98 \%$ to $44.46 \%$ (Figure 5). Scavenging ability values exhibited the same behavior as the TEAC values: the highest values were in the L-36 and Red genotypes, and the lowest in L-37. Higher antioxidant capacity in yellow, orange and red genotypes agrees with observations made by GuilGuerrero et al. [24] that antioxidant capacity in C. annuum genotypes is comparable to that of commercial antioxidants, with the highest activity in orange, red and yellow genotypes.

\subsection{2. ß-Carotene Decolorization Assay}

b-carotene decolorization is an effective antioxidant activity assay. In the absence of an antioxidant, b-carotene undergoes rapid discoloration since the free linoleic acid radical attacks the $\beta$-carotene molecule, which loses its double bonds and consequently its characteristic orange color. During the 120-min decolorization trial, antioxidant capacity decreased over time in the studied genotypes (Figure 6). Values ranged from $36 \%$ to $57 \%$ b-caro-

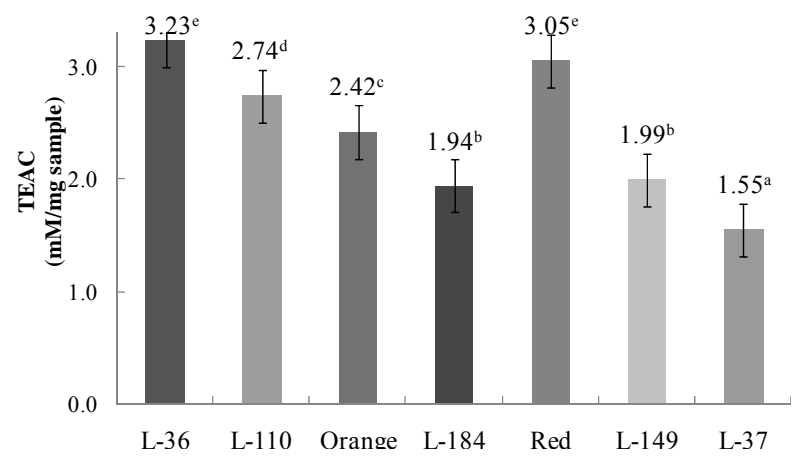

Figure 4. Trolox equivalent antioxidant capacity (TEAC) in $C$. chinense Jacq. genotypes. Data are presented as means $(n=3) .{ }^{a-e}$ Different superscript letters indicate statistical difference $(p<0.05)$.

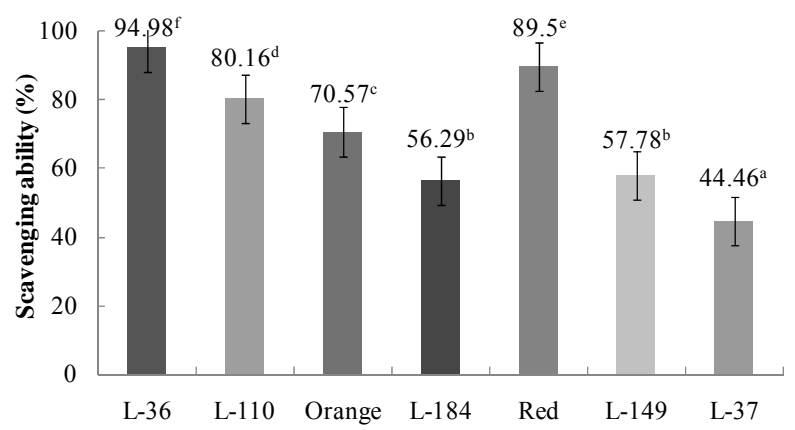

Figure 5. Scavenging ability in Capsicum chinense Jacq. genotypes. Data are presented as means $(n=3) .{ }^{a-f}$ Different superscript letters indicate statistical difference $(p<0.05)$. 


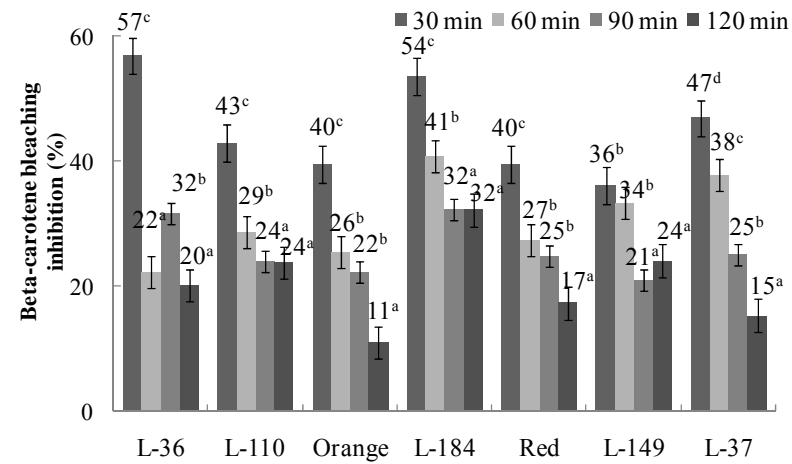

Figure 6. ß-carotene bleaching inhibition in Capsicum chinense Jacq. genotypes. Data are presented as means $(n=3)$. ${ }^{a-c}$ Different superscript letters indicate statistical difference $(\mathbf{p}<0.05)$.

tene bleaching during the first 30 minutes, with L-36 having the highest percentage and L-149 the lowest. After 120 minutes, values ranged from $11 \%$ to $32 \%$. Overall, L-149 was the most stable antioxidant since its capacity decreased only $33 \%$ after 120 minutes.

Phenolic compounds, carotenoids and ascorbic acid can contribute to antioxidant activity in fruits, vegetables and grain products [29]. Free radical scavenging is one of the known mechanisms by which antioxidants inhibit the lipid oxidation caused by free radicals. The high polyphenols, carotenoids and ascorbic acid contents observed here in all the genotypes suggest that their observed antioxidant activities are largely due to their antioxidant content. The present results provide useful and important data for researchers to augment the antioxidant capacity and functional value of Habanero pepper in the food and nutraceutical industries.

\section{Conclusion}

Fruit from the seven studied Habanero chili genotypes is apparently good sources of antioxidants, including ascorbic acid, carotenoids and polyphenols. Habanero fruit can be consumed directly or used in extracts to increase nutritional value in different foods and diets. Development and consumption of Habanero pepper genotypes with high antioxidant activity may help in decreasing the incidence of certain types of diseases in humans.

\section{Acknowledgements}

This research was supported by the Fundación PRODUCE AC-Yucatán, México (Project "Determinación de las propiedades funcionales del chile habanero").

\section{REFERENCES}

[1] B. Halliwell, "Reactive Species and Antioxidants," Redox Biology Is a Fundamental Theme of Aerobic Life," Plant
Physiology, Vol. 141, No. 2, 2006, pp. 312-322. doi:10.1104/pp.106.077073

[2] G. Oboh and J. B. T. Rocha, "Distribution and Antioxidant Activity of Polyphenols in Ripe and Unripe Tree Pepper (Capsicum pubescens)," Journal of Food Biochemistry, Vol. 31, No. 4, 2007, pp. 456-473. doi:10.1111/j.1745-4514.2007.00123.x

[3] B. C. Adedayo, G. Oboh and A. A. Akindahunsi, "Changes in the Total Phenol Content and Antioxidant Properties of Pepperfruit (Dennettiatripetala) with Ripening," African Journal of Food Science, Vol. 4, No. 6, 2010, pp. 403409.

[4] O. T. Ademoyegun, T. A. Fariyike and R. B. AminuTaiwo, "Effects of Poultry Droppings on the Biologically Active Compounds in Capsicum annum L. (var. Nsukka yellow)," Agriculture and Biology Journal of North America, Vol. 2, No. 4, 2011, pp. 665-672. doi:10.5251/abjna.2011.2.4.665.672

[5] G. Antonious, L. Lobel, T. Kochhar, T. Berke and R. Jarret, "Antioxidants in Capsicum chinense: Variation among Countries of Origin," Journal of Environmental Science and Health, Part B, Vol. 44, No. 6, 2009, pp. 621-626. doi:10.1080/03601230903000727

[6] C. O. Perera and G. M. Yen, "Functional Properties of Carotenoids in Human Health," International Journal of Food Properties, Vol. 10, No. 2, 2007, pp. 201-230. doi:10.1080/10942910601045271

[7] Y. J. Surh and S. K. Seoul, "Anti-Tumor Promoting Potential of Selected Spice Ingredients with Oxidative and Anti-Inflammatory Activities," Food and Chemical Toxicology, Vol. 40, No. 8, 2002, pp. 1091-1097. doi:10.1016/S0278-6915(02)00037-6

[8] K. A. Naidu, "Vitamin C in Human Health and Disease Is Still a Mystery? An Overview," Nutrition Journal, Vol. 2, 2003, pp. 2-7. doi:10.1186/1475-2891-2-7

[9] M. Nadeem, F. Muhammad Anjum, M. Rafiq Khan, M. Saeed and A. Riaz, "Antioxidant Potential of Bell Pepper (Capsicum annum L.) a Review," Pakistan Journal of Food Science, Vol. 21, No. 1-4, 2011, pp. 45-51.

[10] E. Cázares-Sánchez, P. Ramírez-Vallejo, F. Castillo-González, M. Soto-Hernández, M. T. Rodríguez-González and J. L. Chávez-Servia, "Capsaicinoids and Preference of Use in Different Morphotypes of Chili Peppers (Capsicum annum L.) of East-Central Yucatán," Agrociencia, Vol. 39, No. 6, 2005, pp. 627-638.

[11] A. Rodríguez-Maturino, A. Valenzuela-Solorio, R. Troncoso-Rojas, D. González-Mendoza, O. Grimaldo-Juarez, M. Aviles-Marin and L. Cervantes-Diaz, "Antioxidant Activity and Bioactive Compounds of Chiltepín (Capsicum annum var. Glabriusculum) and Habanero (Capsicum chinense): A Comparative Study," Journal of Medicinal Plants Research, Vol. 6, No. 9, 2012, pp. 1758-1763.

[12] V. L. Singleton, R. Orthofer and R. M. Lamuela-Raventos, "Analysis of Total Phenols and Other Oxidation Substrates and Antioxidants by Means of Folin-Ciocalteu Reagent," Methods in Enzymology, Vol. 299, No. 1, 1999. pp. 152-178. doi:10.1016/S0076-6879(99)99017-1

[13] D. B. Rodriguez-Amaya and M. Kimura, "Harvest Plus 
Handbook for Carotenoid Analysis," Harvest Plus Technical Monograph 2. Washington DC and Cali, Colombia. International Food Policy Research Institute (IFPRI) and International Center for Tropical Agriculture (CIAT), 2004.

[14] AOAC, "Official Methods of Analysis of the Association of Official Analytical Chemists," 15th Edition, Association of Official Analytical Chemists, Arlington, 1990, pp. 1058-1059.

[15] A. Pukalskas, T. Van Beek, R. Venskutonis, J. Linssen, A. Van Veldhuizen and A. Groot, "Identification of Radical Scavengers in Sweet Grass (Hierochloeodorata)," Journal of Agricultural and Food Chemistry, Vol. 50, No. 10, 2002, pp. 2914-2919. doi:10.1021/jf011016r

[16] H. E. Miller, "A Simplified Method for the Evaluation of Antioxidants," Journal of American Oil Chemists Society, Vol. 48, No. 2, 1971, pp. 91-97. doi:10.1007/BF02635693

[17] D. Montgomery, "Diseño y Análisis de Experimentos," Limusa-Wiley, Mexico City, 2004.

[18] A. Marín, F. Ferreres, F. A. Tomás-Barberán and M. Gil, "Characterization and Quantitation of Antioxidant Constituents of Sweets Pepper (Capsicum annum L.)," Journal of Agricultural and Food Chemistry, Vol. 55, No. 12, 2004, pp. 3861-3869. doi:10.1021/jf0497915

[19] D. Zhang and Y. Hamauzu, "Phenolic Compounds, Ascorbic Acid, Carotenoids and Antioxidant Properties of Green, Red and Yellow Peppers," Journal of Food, Agriculture and Environment, Vol. 1, No. 2, 2003, pp. 22-27.

[20] F. Menichini, R. Tundis, M. Bonesi, M. R. Loizzo, F. Conforti, G. Statti, B. De Cindio, P. J. Houghton and F. Menichini, "The Influence of Fruit Ripening on the Phytochemical Content and Biological Activity of Capsicum chinense Jacq. cv Habanero," Food Chemistry, Vol. 114, No. 2, 2009, pp. 553-560. doi:10.1016/j.foodchem.2008.09.086

[21] R. Tundis, M. R. Loizzo, F. Menichini, M. Bonesi, F. Conforti, G. Statti, D. De Luca, B. De Cindio and F. Menichini, "Comparative Study on the Chemical Composition Antioxidant Properties and Hypoglycaemic Activities of Two Capsicum Annum L. Cultivars (Acuminatum Small and Cerasiferum)," Plant Foods for Human Nutrition, Vol. 66, No. 3, 2011, pp. 261-269.

\section{doi:10.1007/s11130-011-0248-y}

[22] C. Kevers, M. Falkowski, J. Tabart, J. O. Defraigne, J. Dommes and J. Pincemail, "Evolution of Antioxidant Capacity during Storage of Selected Fruits and Vegetables," Journal of Agricultural and Food Chemistry, Vol. 55, No. 21, 2007, pp. 8596-8603. doi:10.1021/jf071736j

[23] D. Hornero-Méndez, R. Gómez-Ladrón de Guevara and M. I. Mínguez-Mosquera, "Carotenoid Biosynthesis Changes in Five Red Pepper (Capsicum annuum L.) Cultivars during Ripening. Cultivar Selection for Breeding," Journal of Agricultural and Food Chemistry, Vol. 48, No. 9, 2000, pp. 3857-3864. doi:10.1021/jf991020r

[24] J. L. Guil-Guerrero, C. Martínez-Guirado, M. M. Rebolloso-Fuentes and A. Carrique-Pérez, "Nutrient Composition and Antioxidant Activity of 10 Pepper (Capsicum Annuun) Varieties," European Food Research and Technology, Vol. 224, No. 1, 2006, pp. 1-9. doi:10.1007/s00217-006-0281-5

[25] O. Collera-Zúñiga, F. G. Jiménez and R. M. Gordillo, "Comparative Study of Carotenoid Composition in Three Mexican Varieties of Capsicum annuum L.," Food Chemistry, Vol. 90, No. 1-2, 2005, pp. 109-114. doi:10.1016/j.foodchem.2004.03.032

[26] M. Suhaj, "Spice Antioxidants Isolation and Their Antiradical Activity: A Review," Journal of Food Composition and Analysis, Vol. 19, No. 6-7, 2006. pp. 531-537. doi:10.1016/i.jfca.2004.11.005

[27] E. Alvarez-Parrilla, L. De la Rosa, R. Amarowicz and F. Shahidi, "Antioxidant Activity of Fresh and Processed Jalapeño and Serrano Peppers," Journal of Agricultural and Food Chemistry, Vol. 59, No. 1, 2011, pp. 163-173. doi:10.1021/jf103434u

[28] R. Re, N. Pellegrini, A. Proteggente, A. Pannala, M. Yang and C. Rice-Evans, "Antioxidant Activity Applying an Improved ABTS Radical Cationde Colorization Assay," Free Radical and Biology Medicine, Vol. 26, No. 9-10, 1999, pp. 1231-1237. doi:10.1016/S0891-5849(98)00315-3

[29] Y. S. Velioglu, G. Mazza, L. Gao and B. D. Oomah, “Antioxidant Activity and Total Phenolics in Selected Fruits, Vegetables, and Grain Products," Journal of Agricultural and Food Chemistry, Vol. 46, No. 10, 1998, pp. 41134117. doi:10.1021/jf9801973 